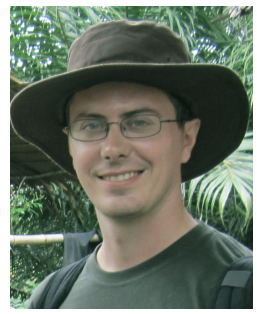

\title{
TROPICAL WETLANDS AND REDD+: THREE UNIQUE SCIENTIFIC CHALLENGES FOR POLICY
}

Daniel A Friess ${ }^{1}$

Assoc Professor

Department of Geography,

National University of Singapore.

The carbon sequestration and storage value of terrestrial habitats is now increasingly appreciated, and is the basis for Payment for Ecosystem Service (PES) policies such as REDD+. Tropical wetlands may be suitable for inclusion in such schemes because of the disproportionately large volume of carbon they are able to store. However, tropical wetlands offer a number of unique challenges for carbon management and policy compared to terrestrial forest systems: 1) Tropical wetlands are dynamic and subject to a wide range of physical and ecological processes that affect their long-term carbon storage potential - thus, such systems can quickly become a carbon source instead of a sink; 2) Carbon dynamics in tropical wetlands often operate over longer timescales than are currently covered by REDD+ payments; and 3) Much of the carbon in a tropical wetland is stored in the soil, so monitoring, reporting and verification (MRV) needs to adequately encapsulate the entire ecosystem and not just the vegetative component. This paper discusses these physical and biological concepts, and highlights key legal, management and policy questions that must be considered when constructing a policy framework to conserve these crucial ecosystems.

\section{Introduction}

Tropical wetlands (primarily mangroves and peat swamp forests) provide a multitude of important ecosystem services such as coastal protection, pollutant assimilation, water retention and flood alleviation, nutrient production, and support of offshore fisheries and livelihoods. ${ }^{2}$ Tropical wetlands are also carbon rich; mangroves, for example, can contain four to six times as much carbon as other terrestrial forest types, ${ }^{3}$ and peat swamps accumulate extensive carbon stores in large peat domes that have formed over thousands of years. These carbon storage and sequestration roles are major reasons why there is growing interest in finding ways of better incorporating tropical wetlands into Payment for Ecosystem Services (PES) schemes such as Reducing Emissions from Deforestation and Forest Degradation + (REDD+), especially in the wake of the United Nations Framework Convention on Climate Change (UNFCCC) conference held in Cancun, Mexico in 2010 (COP-16).

REDD+ is a strategy aimed at protecting important terrestrial forest habitats from deforestation. Although including tropical wetlands into the REDD+ program is attractive, the challenges of effectively doing so are currently huge because:

1. Tropical wetlands are inherently ephemeral and dynamic ecosystems, which are controlled by drivers and stressors that are not apparent in terrestrial forest ecosystems.

2. Carbon dynamics in tropical wetlands operate on timescales that may not be policy-relevant.

3. In contrast to terrestrial forests, most carbon in tropical wetlands is stored below ground in soil and peat. At present there are no accurate monitoring, reporting and verification (MRV) tools for determining stores of the below ground stocks and their accumulation of carbon through time.

\footnotetext{
${ }^{1}$ The research described herein has been funded by the Singapore-Delft Water Alliance (R-303-001-024-414) and the Department of Geography, National University of Singapore (R-109-000-141-133). This paper has benefited greatly from ongoing discussions with Vina Dharmarajah (Nature Society Singapore), Lye Lin Heng, Koh Kheng Lian and Jacob Phelps (National University of Singapore).

2 C Lacambra et al, 'Bioshields: Using Mangroves to Reduce Disaster Vulnerability and Improve Livelihoods' in Renaud, Sudmeier-Rieux and Estrella (eds), The Role of Ecosystems in Disaster Reduction (United Nations University Press, 2013).

3 D C Donato et al, 'Mangroves Among the Most Carbon-Rich Forests in the Tropics' (2011) 4 Nature Geoscience 293.
} 
As a wetland scientist, I have written this essay with the aim of introducing, from a physical and biological viewpoint, some of the unique attributes of tropical coastal wetlands in order to inform and prompt further legal and policy debate. This paper discusses the main scientific challenges to incorporating tropical wetlands into PES schemes, and poses questions that policymakers should consider to ensure successful REDD+ implementation.

This paper also aims to highlight the need for collaboration among scientists and policy makers to develop the foundation for robust evidence-based policy. Many of the policy questions raised here are the result of unique physical or biological attributes and processes that need to be understood and measured in order to deploy the most effective management, legal or policy instrument. Tropical wetlands are chronically understudied when compared to other ecosystems (due to geographical location and issues of access). Consequently, significant knowledge gaps exist in understanding their dynamics and stability. ${ }^{4}$ In many countries there is even a lack of basic information about how much tropical wetland is being lost. ${ }^{5}$

Conservation policy interventions are most effective when informed by a robust and transparent base of scientific knowledge. ${ }^{6}$ In order to create legitimate and transparent knowledge for integration into evidence-based policy there is a need for increased scientific understanding of the dynamic nature of wetlands.

\section{Tropical wetlands are dynamic and controlled by external factors}

Physical and biological thresholds determine the stability of tropical wetlands. ${ }^{7}$ These thresholds relate to species' tolerances to tidal flooding and waves (mangroves) and drainage and dewatering of peat soils, and (often human-induced) fire (peat swamps). Stressors for mangroves include ship wake caused by boat traffic and harbour capacity along the coast, and bridge/causeway construction and coastal land reclamations at some distance from the mangrove causing significant changes in prevailing hydrodynamic (current and wave) conditions. ${ }^{8}$ The stability of peat swamp carbon reserves is affected by drainage inside and outside the area, as well as illegal fires for land clearance that spread through neighbouring forests. ${ }^{9}$ The temporal and spatial scales of stressors on tropical wetlands have important implications for decisions about the most appropriate policy or management instrument.

Site-scale stressors are local and often operate over short periods. For example, the mangrove site at Tanjung Piai National Park in southern Johor, Peninsular Malaysia, is protected through legal designations. However, the mangrove site fronts the Malacca Straits, an essential shipping lane for traffic into Singapore and Malaysia. The wake of increasing numbers of ships has caused significant erosions of the shoreline with a devastating effect on the mangrove ${ }^{10}$ (and subsequent release of carbon), as shown in Figure 1.

Regional-scale stressors, such as peat swamp forest fires caused by illegal land clearance, affect larger areas. It is estimated that in 1997, more than 2.57 gigatonnes (2 570000000 tonnes) of carbon was released from the whole of Indonesia due to peat swamp burning. ${ }^{11}$

On a global scale, perhaps the greatest indirect stressor on tropical wetlands is accelerated sea level rise (SLR).

The choice of instrument for conserving wetlands and peat swamps needs to take into account the stressor and scale of the issue(s) affecting the lands; for example, a policy instrument aimed at reducing ship wake

${ }^{4}$ D A Friess et al, 'Are All Intertidal Wetlands Naturally Created Equal? Bottlenecks, Thresholds and Knowledge Gaps to Mangrove and Saltmarsh Ecosystems' (2012) 87 Biological Reviews 346.

${ }^{5}$ D A Friess and E L Webb, 'Bad Data Equals Bad Policy: How To Trust Rates of Ecosystem Loss When There Is So Much Uncertainty?' (2011) 38 Environmental Conservation 1.

' M R Rands et al, 'Biodiversity Conservation: Challenge Beyond 2010' (2010) 329 Science 1298; R T Watson, 'Turning Science Into Policy: Challenges and Experiences From the Science-Policy Interface' (2005) 260 Philosophical Transactions of the Royal Society B 471.

7 Friess et al, above n 5; J H Wösten et al, 'Interrelationships Between Hydrology and Ecology In Fire Degraded Tropical Peat Swamp Forests' (2006) 22 International Journal of Water Resources Development, 157; K W Krauss et al, 'Environmental Drivers in Mangrove Establishment and Early Development: A Review' (2008) 89 Aquatic Botany 105.

8 D A Friess et al, 'Mandai Mangrove, Singapore: Lessons for the Conservation of Southeast Asia's Mangroves' (2012) S25 Raffles Bulletin of Zoology 55.

9 Ministry of Natural Resources and Environment, Malaysia, Danida, GEF and UNDP, Malaysia's Peat Swamp Forests: Conservation and Sustainable use (United Nations Development Programme, Malaysia. 2006).

${ }^{10}$ V C Chong, 'Sustainable Utilization and Management of Mangrove Ecosystems of Malaysia' (2006) 9 Aquatic Ecosystem Health and Management 249.

${ }^{11}$ S E Page et al, 'The Amount of Carbon Released From Peat and Forest Fires In Indonesia In 1997' (2002) 420 Nature 61. 
addresses a different physical issue and spatial/temporal scale compared to a policy aimed at reducing the spread of illegal peat forest fires.

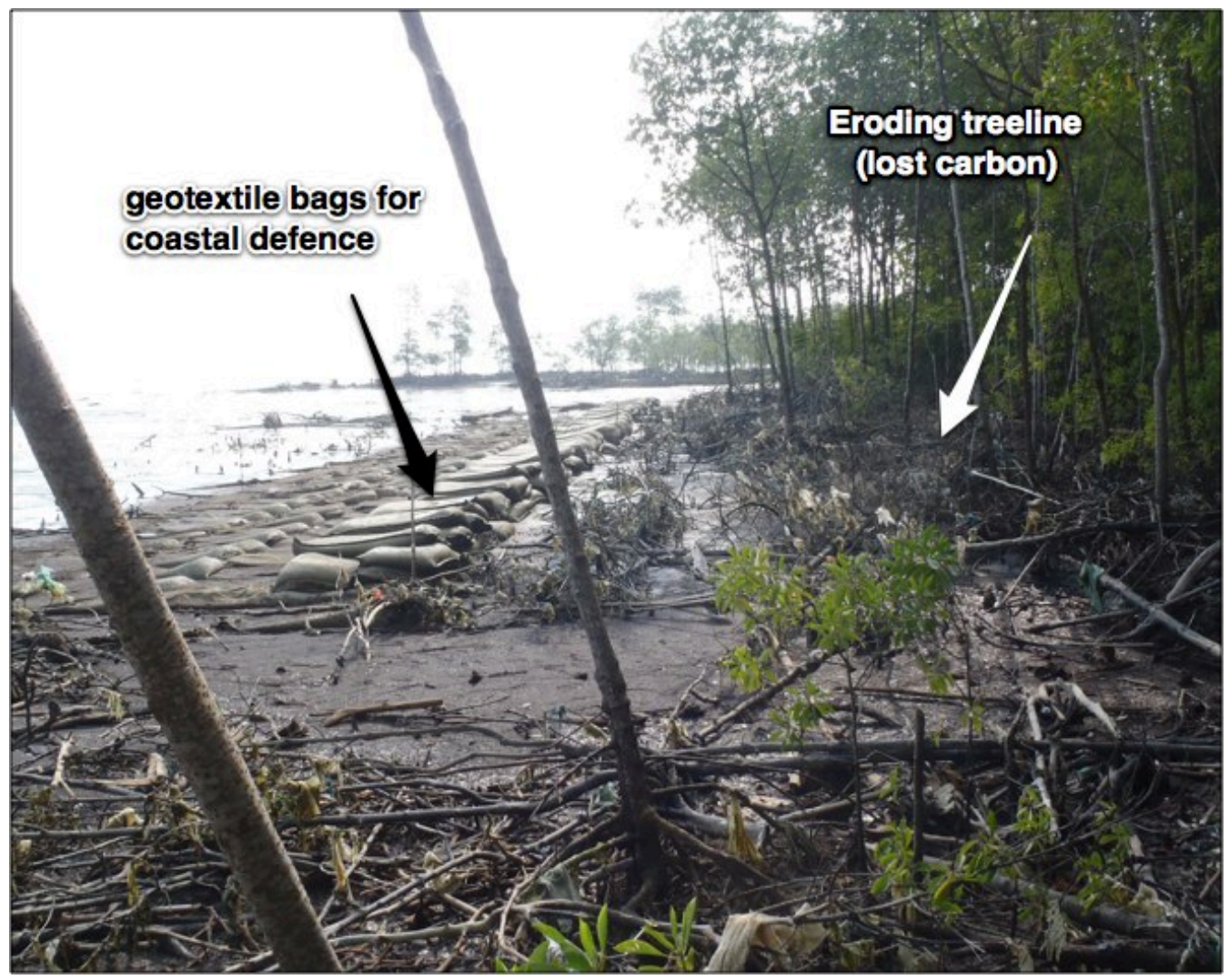

Figure 1: Severe erosion is experienced at Tanjung Piai National Park, despite extensive coastal protection measures (eg sandbags in the photo), due to the movement of large container ship and tanker traffic less than three kilometers offshore. (February 2011).

\section{Questions for policymakers}

The dynamic nature of tropical wetlands, and the various stressors that contribute to their dynamism raises important and unique questions for policy.

1. What interventions are most effective for managing a dynamic group of ecosystems?

It is important to consider the most appropriate intervention and not simply follow a particular proffered programme (such as REDD+) as a general panacea to address wetland loss. It may turn out that if a PES policy does not address the biophysical drivers of habitat loss in a particular wetland area, it may not be the most effective tool.

2. Should REDD+ schemes produce a surplus of carbon credits as a buffer to wetland dynamics? If a suitable policy instrument cannot be identified (point 1), other options should be investigated that provide a buffer to natural and anthropogenically-induced wetland dynamics. Neeff and Ascui describe the mechanisms that create a buffer of carbon credits that allow periods of non-permanence to be weathered, including fungible and temporary credit structures. ${ }^{12}$ However the authors note that several issues, such as demand and price depression of temporary credits, and credit reserves need to be developed further and implemented as a mandatory step in wetland REDD+.

\footnotetext{
${ }^{12}$ T Neeff and F Ascui, 'Lessons From Carbon Markets for Designing an Effective REDD Architecture' (2009) 9 Climate Policy 306.
} 


\section{Temporal scales of carbon dynamics may not fit policy timescales}

Temporal scales of wetland ecosystem growth and succession may not operate on timescales that are policy-relevant. Alongi describes timescale in tropical wetland carbon storage (biomass) versus carbon accumulation (primary production). ${ }^{13}$ Some PES schemes may only be interested in financing the amount of carbon protected from deforestation (long-term storage), or the amount of carbon sequestered from the atmosphere. The initial instinct may be to protect old growth wetland forests with large biomass trees that have a greater overall carbon store. However, after a certain age, such forests reach a plateau of primary production, so carbon accumulation rates do not increase further. ${ }^{14}$ Thus, conserving old and stable mangroves may do little to sequester additional carbon from the atmosphere. It is also possible to make the argument that it is beneficial to plant mangrove saplings (which is not applicable in some PES schemes) and thereby accumulate increasing rates of carbon when compared to old mangrove forests. However, mangrove trees are small, and the total amount of carbon that can be accumulated and stored in them is, therefore, small.

However, the discussion about carbon under PES schemes concerns the temporal scale of carbon dynamics in the above ground biomass proportion of forest carbon when, in wetlands, a large proportion of carbon is stored below ground (see section below). Below ground carbon stocks in mangroves and peat swamps have been accumulating as peat over centuries at a rate of millimetres per year (Figure 2a) through the trapping of sediments and organic matter. ${ }^{14}$ Inexpensive point methods exist to measure such small changes in the wetland soil (see, for example, Figure $2 \mathrm{~b}$ ), but over the 20 -year period of a typical REDD+ project ${ }^{15}$ there $^{2}$ will be little change in accumulation. Thus, the slow accumulation of below ground carbon suggests that a PES scheme that values the carbon 'locked in' over the timescale of the project will be more successful than those that value rates of sequestration.
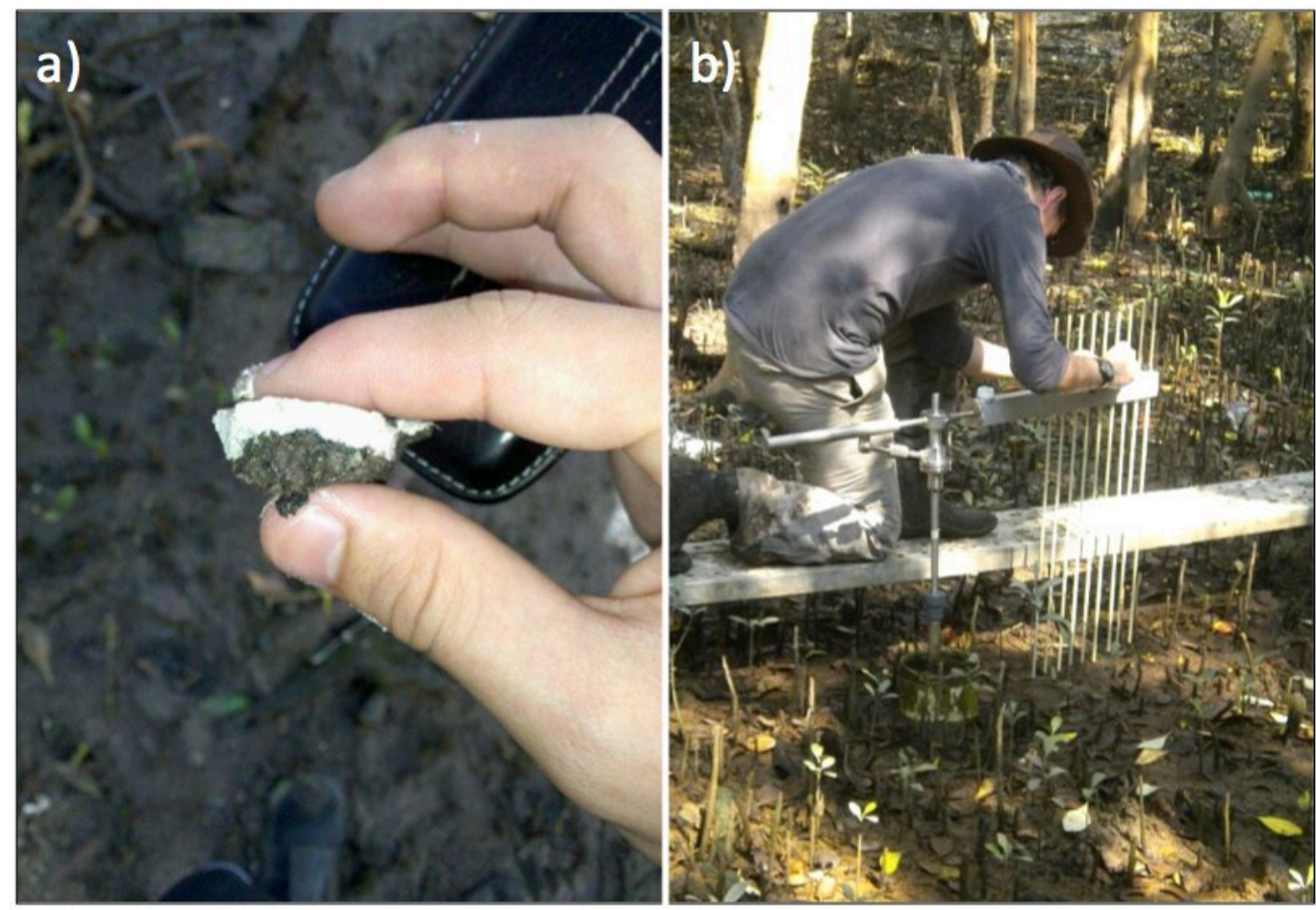

Figure 2: Slow rates of sediment accumulation eg over 1 year (a) can be measured precisely using the Rod Surface Elevation Table (b) - an instrument that is drilled into the bedrock and uses pins to measure millimetre change in mangrove sediment accumulation and/or loss at six-monthly intervals. This data can be easily converted into rates of carbon accumulation, and should be a method that is incorporated into all wetland PES schemes that monetise carbon sequestration.

\footnotetext{
${ }^{13}$ D M Alongi, 'Carbon Payments for Mangrove Conservation: Ecosystem Constraints and Uncertainties of Sequestration Potential' (2011) 14 Environmental Science and Policy 462.

${ }^{14}$ D Taylor et al, 'Late Quaternary Peat Formation and Vegetation Dynamics In a Lowland Tropical Swamp, Nee Soon, Singapore' (2001) 171 Paleogeography, Paleoclimatology, Paleoecology 269.

15 J Phelps E L Webb and L P Koh, 'Risky Business: An Uncertain Future For Biodiversity Conservation Finance Through REDD+' (2010) 4 Conservation Letters 88.
} 


\section{Questions for policy makers}

1. What forest age class is the most appropriate to protect?

The aim of the PES scheme, and the 'type' of carbon being protected and paid for needs to be clearly stated - is it carbon storage (and reducing the release of stored carbon) or is it sequestration and active removal of carbon dioxide from the atmosphere? Tropical wetlands may be more suited to a focus on the former.

2. What mechanisms are in place to protect carbon stocks and accumulation over timescales that are longer than PES schemes?

Since the below ground carbon stock has taken centuries to accumulate, it cannot be readily replaced if lost after a PES scheme expires. Firm plans need to be made to maintain this carbon stock in perpetuity - beyond the relatively short period of a PES scheme. Indeed, basing all funding for a protected area on a single scheme such as REDD+ may be 'risky business'. ${ }^{16}$

\section{The majority of carbon in tropical wetlands is stored below ground}

MRV of carbon stocks, accumulation and fluxes has faced a number of technical and institutional challenges in terrestrial forests, ${ }^{17}$ though such challenges are surmountable; there are now robust carbon stock and emission assessments over large - even global - scales. ${ }^{18}$ Indeed, it has been suggested that issues of MRV for terrestrial forests may now be more political and institutional rather than technical. ${ }^{19}$

The same does not hold true for the MRV of tropical wetland carbon; technical challenges remain a huge problem due to the location of the stored carbon. While in most terrestrial forests the majority of carbon is stored in above ground biomass, tropical wetlands store most of their carbon below the ground, predominantly in deep and long-term peat deposits. Donato et al estimated that, for mangroves in the Indo-Pacific, between 49 and 98 per cent of a mangrove's total carbon pool is stored below ground. ${ }^{20}$ However, Donato et al's study only sampled the top three meters of the soil column, whereas the depth of mangrove soils may reach five to eight meters in Southwest Thailand and eleven to sixteen meters in Singapore (author's personal observations). Thus, current estimates of carbon stores may be highly conservative.

At present the rapid and accurate MRV of the total tropical wetland carbon pool is almost impossible because:

1. There is no accurate measure of below ground carbon at increasing scales. Measurements are sparse and point-based due to huge manpower requirements.

2. Technical limitations exist for conducting deep soil sampling, so it is difficult to capture the carbon in the full soil profile.

3. Large knowledge gaps exist with regards to the role of root production in contributing to the total belowground carbon pool. ${ }^{21}$

4. Below ground carbon stocks are spatially variable due to the variability of organic inputs, sediment characteristics, soil profile depth etc. Thus it is difficult to generalise point measurements to the site scale.

5. Some point-based methods exist to measure soil and below ground carbon accumulation (Figure $2 \mathrm{~b}$ previously), though sample size is small and the available data is skewed geographically to the US,

\footnotetext{
16 Ibid.

17 D J Baker et al, ‘Achieving Forest Carbon Information With Higher Certainty: A Five-part Plan’ (2010) 13 Environmental Science and Policy 249; J C Fox et al, 'Protocols For Field Sampling of Forest Caarbon Pools For Monitoring, Reporting and Verification of REDD' (2010) Geoscience and Remote Sensing IGARSS 2010 IEEE International, 1509; A Gupta et al, In Pursuit of Carbon Accounting: The Politics of REDD+ Measuring, Reporting and Verification Systems. (2012) 4 Current Opinion in Environmental Sustainability 726.

${ }^{18}$ S S Saatchi et al. 'Benchmark Map of Forest Carbon Stocks In Tropical Regions Across Three Continents' (2011) 108 Proceedings of the National Academy of Sciences USA 9899; N L Harris et al, 'Baseline Map of Carbon Emissions From Deforestation in Tropical Regions' (2012) 336 Science 1573.

${ }^{19}$ Kate Evans, 'Scientists Show Technical Concerns No Longer an Obstacle To Progress On REDD+ (21 December 2012) $<$ http://blog.cifor.org/13390/scientists-show-technical-concerns-no-longer-an-obstacle-to-progress-onredd/\#.UPZfpDmjOJU>.

${ }^{20}$ Donato et al, above $\mathrm{n} 3$.

${ }^{21}$ D M Alongi, 'Carbon Sequestration In Mangrove Forests' (2012) 3 Carbon Management 313.
} 
Central America and Australia. ${ }^{22}$ Thus, there is a lack of basic information for areas where REDD+ sites might be of most benefit, for example, Southeast Asia.

6. Knowledge gaps exist on the ratio of above/below ground carbon in mangrove forests, and how this ratio might change with forest age, coastal position or geographic location. ${ }^{23}$ This is important to note if policymakers decide to extrapolate a fixed ratio based on a small number of sites as a proxy measure for other sites.

\section{Questions for policy makers}

1. What level of uncertainty are decision-makers and investors willing to tolerate due to our inability to provide accurate total carbon pool estimates?

Technical limitations mean that assessments of below ground, and hence the total mangrove carbon pool, can only be broadly estimated. Carbon accounting and monetisation need to operate within these technical constraints, which - due to the disproportionate amount of below ground carbon - are largely peculiar to tropical wetland systems. Because of constraints to MRV, REDD+ investors and policymakers will likely have to accept lower standards of certainty and scientific verification. ${ }^{24}$ Due to scientific uncertainty, carbon accounting must employ accounting principles of conservativeness to anticipate a lower, more robust estimate of carbon, and minimise the risk of overestimation. This is being addressed somewhat in discussions of terrestrial REDD+ but is even more important for tropical wetlands due to greater information uncertainty.

2. Would other proxies of total carbon pool be acceptable to markets?

Currently, top-down proxies of easy-to-identify structural features (for example vegetation cover), as opposed to bottom-up measurements of fluxes, processes and hidden stores are the basis for measures. ${ }^{28}$ Given the impossibility of below ground carbon stock assessment, other top-down proxies must be defined and tested for suitability and robustness. Depending on the aim of the PES scheme (for example paying for stocks versus paying for sequestration), bottom-up measurements of fluxes may be appropriate, for example measuring rates of carbon accumulation as per Figure $2 b$.

\section{Conclusions}

Several unique aspects of tropical wetlands bring with them a number of specific challenges to the successful implementation of PES schemes. Current REDD+ strategies, designed and piloted primarily in terrestrial forest systems, cannot, at present, adequately address the three main challenges discussed in this paper: first, the need for management, legislative and governance structures that account for the biophysical dynamism of coastal wetlands; second, the need to choose policies that operate adequately over geomorphological and ecological timescales; and third, the need to understand the difficulties of accurate total mangrove carbon determination, and the need to better incorporate treatments of uncertainty into MRV. These scientific challenges are in addition to already-recognised institutional and capacity-building issues for REDD+, though it is the scientific challenges that have received the least attention ${ }^{25}$ and potentially determine the success of REDD+ institutions and structures. This paper has summarised some of the major scientific challenges specific to wetlands in order to begin a discussion on how to address them. The successful conservation of important and imperilled tropical wetland systems can only be brought about through the real and sincere integration of scientific, legal and policy thinking.

${ }^{22}$ E L Webb et al, 'A Global Standard For Monitoring Coastal Wetland Vulnerability to Accelerated Sea Level Rise' (2013) 3 Nature Climate Change 458.

${ }^{23}$ Alongi, above $\mathrm{n} 28$.

${ }^{24} \mathrm{M}$ Jonas et al 'Lessons to be Learned from Uncertainty Treatment: Conclusions Regarding Greenhouse Gas Inventories' in M Jonas et al (eds), Greenhouse Gas Inventories: Dealing with Uncertainty (Springer. 2011) 339.

${ }^{25}$ G P Asner, 'Painting the World REDD: Addressing Scientific Barriers to Monitoring Emissions from Tropical Forests' (2011) 6 Environmental Research Letters 021002. 